Article

\title{
Sustainable Energy Development in Saudi Arabia
}

\section{Mounir Belloumi ${ }^{1,2, \dagger, *}$ and Atef Saad Alshehry ${ }^{2, \dagger}$}

1 Laboratoire du Management d'Innovation et du Developpement Durable, University of Sousse, Sousse 4023, Tunisia

2 College of Administrative Sciences, Najran University, Najran 1988, Saudi Arabia;

E-Mail: atsalshehry@nu.edu.sa

$\dagger$ These authors contributed equally to this work.

* Author to whom correspondence should be addressed; E-Mail: mounir.balloumi@gmail.com; Tel.: +966-5309-48710; Fax: +966-1754-28888.

Academic Editor: Marc A. Rosen

Received: 24 December 2014 / Accepted: 21 April 2015 / Published: 27 April 2015

\begin{abstract}
The main objective of this research is to study the role of energy consumption in economic growth in Saudi Arabia over the period of 1971-2012 using the autoregressive distributed lag (ARDL) cointegration procedure, and based on neoclassical growth, endogenous growth, and ecological-economics viewpoints. Our empirical results show the existence of a cointegrating relationship between the different variables investigated. In addition, all the inputs (conventional and non-conventional) Granger cause economic growth in both the short and long runs. Our findings confirm the energy-led growth hypothesis in the case of Saudi Arabia. Hence, energy conservation policies may deteriorate economic growth in Saudi Arabia if they are not followed by measures that improve energy efficiency, energy saving technologies and encourage the investment and use of renewable energy sources such as solar and wind energies that can participate in the attenuation of climate changes.
\end{abstract}

Keywords: ARDL bounds testing; energy-led growth hypothesis; Saudi Arabia

\section{Introduction}

Even though neoclassical theory states that energy is neutral to economic growth, historically, energy shocks have affected global economic growth. This observation shows the key role of energy consumption 
in economic growth [1,2]. According to the ecological and biophysical models, energy is the main factor of production $[3,4]$. The production of goods is straightly related to the use and the availability of energy, which is considered as the primary factor of production. The main aim of this study is to examine the role of energy consumption in economic growth for an oil producing and exporting country (OPEC), such as Saudi Arabia, using the autoregressive distributed lag (ARDL) Bounds testing to cointegration over the period 1971-2012. In order to control for potential omitted-variable biases and take into account the neoclassical, endogenous growth and ecological economics view points, we consider a model where real GDP is explained by employment, capital, and human capital in addition to energy consumption (for more details, see [4-6]). Generally, it is known that the level of energy consumption is very high in the majority of OPEC members, and mainly in Saudi Arabia, due to the low levels of national fuel prices and energy efficiency. Energy is over subsidized in Saudi Arabia. Nowadays, the country is under pressure to increase fuel prices and reduce fuel subsidization. If we find that energy consumption boosts economic growth in Saudi Arabia, a policy aiming to reduce energy consumption might lead to undesirable results concerning economic growth. We should suggest some other measures such as energy efficiency, investment in renewable energies such as solar and wind energies and capital formation that could lead to economic growth and increase employment, where the demand for labor is increasing.

The causal relationship between energy consumption and economic growth has been well studied since the seminal paper of [7]. However, until now the empirical findings are divergent sometimes, even for the same country. Different empirical research has used a variety of econometric techniques and variables over various periods for different countries or groups of countries at aggregated and disaggregated levels. In this context, by using a meta-analysis of 51 works on energy-growth nexus, Menegaki (2014) [8] found that the long run impact of energy consumption on economic growth is dependent of the variables investigated, the data span, and the cointegration technique used.

The role of energy in economic growth has interested researchers since the first oil crisis of 1973. It continues to interest researchers for many reasons. Firstly, the high volatility of fossil fuel prices has largely affected global economic activities and even food security. Secondly, since the industrial revolution, energy has been used in all economic activities. It has become the main engine of the global economy. Thirdly, the use of energy (mainly fossil fuels) is not without negative effects on the global environment and its consequences on climate change has adversely affected human activities.

As reviewed and reported by previous research, there is a large literature on the causal relationship between energy use and economic growth. In this study, we survey mainly the studies including employment and capital as inputs in the energy-growth nexus. The first work on this subject is that of Kraft and Kraft (1978) [7] who studied the relationship between gross national product (GNP) and energy for the United States over the period 1947-1974. By using the Sims causality test, they showed that energy consumption does not cause GNP but the reverse holds. Comparatively to the work of Kraft and Kraft (1978) [7], Akarca and Long (1980) [9] changed only the period of study but they did not find the same result. Their finding showed the absence of causality between the gross national product and energy use for the U.S. over the period 1950-1970. Eight years after the first work of Kraft and Kraft (1979) [7], Erol and Yu (1987) [10] studied the causal relationship between energy consumption and GNP for another six developed countries (Canada, France, Germany, Italy, Japan and the United Kingdom). The authors used both tests of causality of Sims and Granger. The neutral hypothesis of energy was verified for both countries of France and the United Kingdom, whereas the energy-led 
growth hypothesis held only for Canada. The feedback hypothesis was verified for Japan while the conservation hypothesis was found for Germany and Italy.

The above studies considered only the tests of causality between two macroeconomic series. Later many researchers showed that these types of models suffer from the problem of omission of some other variables, which could affect the results. In order to resolve this problem, when studying the relationship between energy consumption and economic growth, many studies have included other variables such as employment, capital, carbon dioxide emissions, etc. For example, when investigating the causal relationship between energy consumption and GNP in United States, Yu and Hwang (1984) [11] included employment as a control variable. Their findings showed the absence of causality in both directions between energy consumption and GNP. The results confirmed the neutral hypothesis.

However, all these previous studies did not check for the non-stationarity of the macroeconomic time series. Hence, since the work of Yu and Hwang (1984) [11], many studies have used the cointegration approaches of Engle and Granger (1987) [12], and Johansen and Juselius (1990) [13] to resolve this problem. As an example of work using the Engle-Granger cointegration technique, Cheng and Lai (1997) [14] studied the relationship between real GDP, energy consumption and employment in the case of Taiwan. They found unidirectional causality running from real GDP to energy consumption. This means that conservative hypothesis holds.

Contrarily to the previous technique, the Johansen-Juselius cointegration approach has been widely used (e.g., [15-19]). For example, Chang et al. (2001) [15] studied the dynamic causal relationships between economic output, energy consumption and employment for Taiwan for the period covering January 1982 to November 1997. Their results supported the energy-led growth hypothesis. Ghali and El-Sakka (2004) [16] used a neo-classical production function where economic output is explained by capital, labor and energy use for Canada. They found bidirectional causality between economic growth and energy use. Yuan et al. (2008) [18] studied the causal relationships between energy consumption, labor, capital and economic output for China using a neo-classical aggregate production function. They used energy consumption at both aggregated and disaggregate levels (electricity consumption, oil consumption and coal consumption). The authors found that the series are cointgrated at both aggregated and disaggregated levels. The results of short run causality are mixed. Stern and Enflo (2013) [19] studied the relationship between energy, capital, labor and economic growth for Sweden over the three periods of 1900-2000, 1950-2000 and the whole period of 1850-2000. Using a VECM, they found that energy Granger causes economic growth for the whole period of 1850-2000, whereas economic growth causes energy for the two other periods.

However, the Johansen's cointegration approach has been criticized by many researchers when using small samples, because the usual unit root and cointegration tests are not powerful in this case. In order to control for the problems associated with small samples, some researchers have made appeal to other methods such as the ARDL bounds testing approach (e.g., [20,21]) and panel unit root and cointegration tests (e.g., [22]).

Sari et al. (2008) [20] studied the relationships between disaggregate energy consumption (coal, natural gas, fossil fuels, conventional hydroelectric power, solar energy, wind energy, wood, and waste), employment and industrial output in the United States using monthly data covering the period of January 2001 to June 2005. They found unidirectional causality running from industrial production to disaggregate energy consumption; except for the case of coal consumption, the reverse holds. Shahbaz et al. (2011) [21] 
included employment as an additional variable to electricity consumption and economic growth when studying the causal relationships between the three variables for Portugal over the period of 1971-2009. Their results showed that there is bidirectional causality between the three variables in the long run. The feedback hypothesis was validated. Lee et al. (2008) [22] analyzed the relationships between energy consumption, capital stock and economic output for a set of 22 OECD countries over the period 1960-2001. They found that the three series are cointegrated and there is a bi-directional causality between economic growth and energy consumption. By studying the energy-growth nexus in 17 Arab countries using the ARDL approach over the period 1980-2011, Shahateet (2014) [23] found that neutrality hypothesis is verified in 16 out of 17 Arab countries including Saudi Arabia.

By taking into account the non-normality assumption, Yildirim and Aslan (2012) [24] studied the causal relationships between energy use, employment, gross fixed capital formation, and economic growth for 17 highly developed OECD countries using the Toda-Yamamoto test framework and the leveraged bootstrapped simulation technique. Their findings indicate the neutrality in the case of Australia, Canada, and Ireland. In the same line, Yalta and Cakar (2012) [25] used a maximum entropy bootstrap to investigate the relationship between energy consumption and economic growth over the period 1971-2007 in the case of China. Overall, their results support the neutrality hypothesis. Salamaliki and Venetis (2013) [4] argued that no previous studies took into account the indirect causality. To do so, they studied the causal relationships between energy consumption, real GDP and capital stock in the group of seven advanced countries by employing two recent methods of Dufour-Pelletier-Renault (2006) [26] and Hill (2007) [27] in order to detect direct and indirect causal effects. They found that in general, real GDP causes energy consumption for this group of countries. Ayres and Voudouris (2014) [28] studied the nonlinear relationships between economic growth with energy use, labor and capital stock in Japan, United Kingdom and United States. They argued that since the industrial revolution, capital stock and energy have played an important role in economic growth.

For the case of Saudi Arabia, empirical studies on energy consumption-economic growth nexus are very restricted. To our knowledge, there are only two studies (Alqudair [29,30]) that focused on Saudi Arabia as a single-country, whereas many other studies ([31-38]) focused on Saudi Arabia in the context of a multi-country study. The results of these studies are mixed and sometimes contradictory. The results of [30-32,37] are conforming to the conservative hypothesis that implies economic growth Granger causes energy consumption in the long run. Squalli (2007) [33], Narayan and Smyth (2009) [34], Sadorsky (2011) [35] and Mohammadi and Parvaresh (2014) [38] validated the feedback hypothesis that states bidirectional causality between energy consumption and economic growth in the long run. Contrarily, Hossein et al. (2012) [29] and Alkhathlan et al. (2012) [36] found an absence of causality between energy consumption and economic growth in the long run. Their findings are conforming to the neutrality hypothesis.

Our study complements the work of Alkhathlan et al. (2012) [29], which is the only one of these studies that used the production function approach. The study of Alqudair [30] is limited to a two-variable specification that investigated the energy use-economic growth nexus. Alkhathlan et al. (2012) [29] studied the relationship between economic growth, carbon dioxide emissions, employment and energy consumption in Saudi Arabia over the period 1980-2008 using both approaches of ARDL Bounds testing and Johansen multivariate cointegration. The authors used a production function framework where they explained economic output by energy consumption, employment and $\mathrm{CO}_{2}$ emissions. Compared to this 
previous study, we do not integrate $\mathrm{CO}_{2}$ emissions; we add real fixed capital formation and human capital as explanatory variables of economic growth and extending the period from 1971 to 2012.

The remainder of our paper is organized as follows. In Section 2, we present the material and methods used to investigate the relationship between real GDP, energy consumption, real fixed capital formation, employment and human capital in the case of Saudi Arabia. We present the data and the different procedures of ARDL cointegration Bounds testing framework. Section 3 presents the empirical results. In Section 4, we discuss our different findings. Finally, Section 5 concludes by some policy implications and recommendations.

\section{Material and Methods}

\subsection{Data Descriptions}

This study is based on annual time series data on real GDP, energy consumption, real fixed capital formation, employment and human capital over the period 1971-2012. Except employment, all the four other time series are sourced from [39]. Time series data on employment are taken from [40].

The variable real GDP is expressed in million 2005 US\$. We note its natural logarithm by Y. Energy consumption refers to the use of primary energy before transformation to other end-use fuels. It is expressed in kiloton of oil equivalent and its natural logarithm is noted by $\mathrm{X}_{1}$. Since a time series on the capital stock is not directly available for Saudi Arabia, it is proxied by the real value of gross fixed capital formation (GFCF). This proxy for capital stock has been used in many previous studies $([41,42])$. It is expressed in million 2005 US\$ and its natural logarithm is noted by $\mathrm{X}_{2}$. Employment is measured by the number of people employed in the different economic activities in Saudi Arabia. It is expressed in thousands of persons and we note its natural logarithm by $\mathrm{X}_{3}$. Human capital is proxied by the ratio of gross tertiary school enrollment. According to the World Bank, it is defined as the ratio of total enrollment, regardless of age, to the population of the age group that officially corresponds to this level of education. We note the natural logarithm of this variable by $\mathrm{X}_{4}$. Descriptive statistics of all variables at their levels and growth rates are presented in Table 1.

Table 1. Descriptive statistics.

\begin{tabular}{cccccccc}
\hline & \multicolumn{4}{c}{ Variable Levels } & \multicolumn{3}{c}{ Growth Rates (\%) } \\
\cline { 2 - 8 } Statistics & $\begin{array}{c}\text { Real } \\
\text { GDP }\end{array}$ & $\begin{array}{c}\text { Energy } \\
\text { Consumption }\end{array}$ & $\begin{array}{c}\text { Real Gross } \\
\text { Fixed Capital } \\
\text { Formation }\end{array}$ & Employment & $\begin{array}{c}\text { Human } \\
\text { Capital }\end{array}$ & $\begin{array}{c}\text { Real } \\
\text { GDP }\end{array}$ & $\begin{array}{c}\text { Energy } \\
\text { Consumption }\end{array}$ \\
\hline Mean & $239,836.9$ & $80,256.39$ & 392.200 & 4813.400 & 16.123 & 4.69 & 8.01 \\
Median & $223,325.0$ & $74,413.64$ & 299.901 & 4883.000 & 11.292 & 4.96 & 6.68 \\
Maximum & $497,620.1$ & $197,000.0$ & 1118.271 & 8935.555 & 50.936 & 24.28 & 40.81 \\
Minimum & $72,547.85$ & 6250.783 & 25.773 & 1539.199 & 1.635 & -11.76 & -16.30 \\
Standard & $97,242.47$ & $56,313.61$ & 290.294 & 2261.481 & 12.045 & 7.11 & 11.35 \\
Deviation & & 42 & 42 & 42 & 42 & 41 & 41 \\
Observations & 42 & 42 & & & &
\end{tabular}

Figure 1 gives a plot of the annual growth rates of real GDP and energy consumption over the period 1971-2012. 


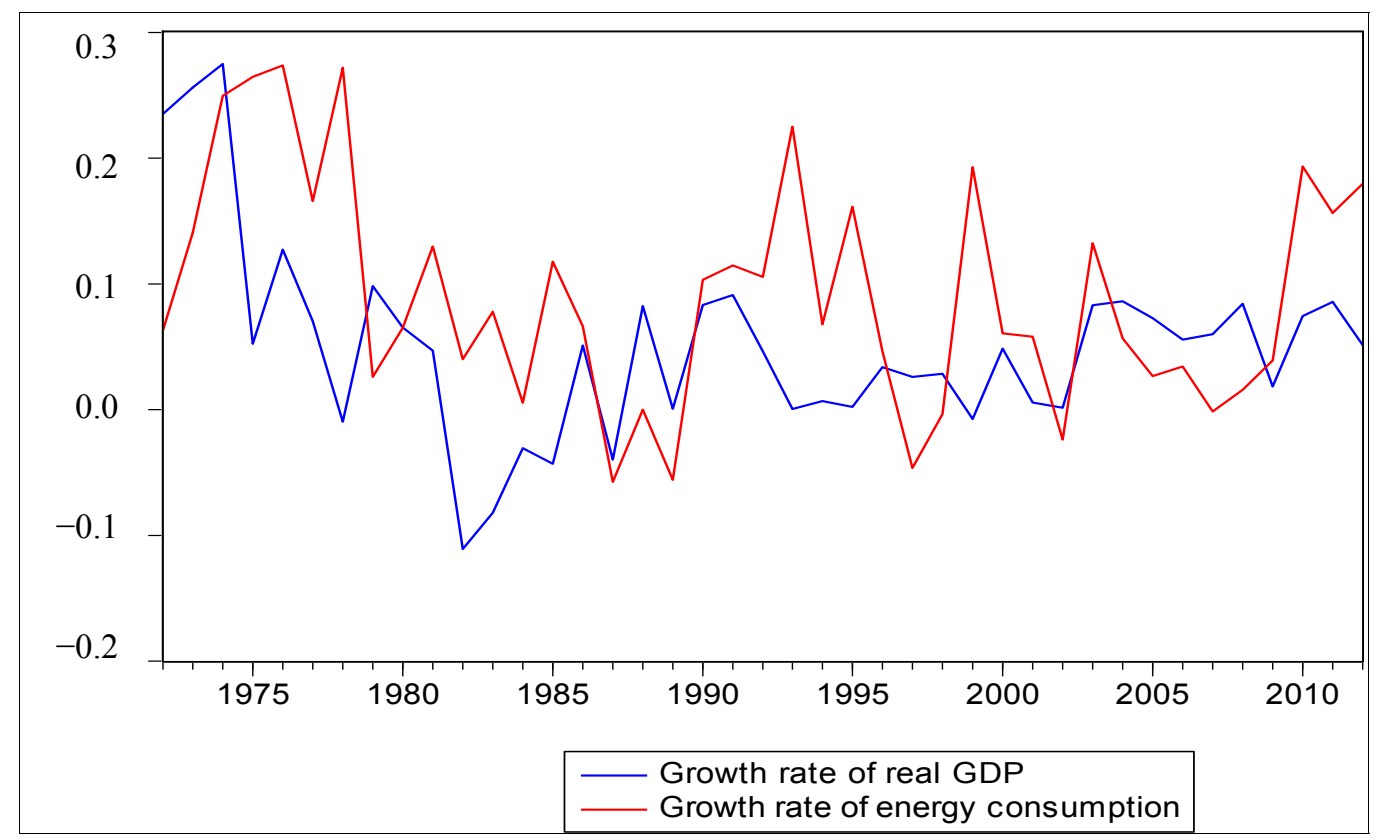

Figure 1. Annual growth rates of energy consumption and real GDP.

\subsection{ARDL Bounds Testing}

Our study is based on Autoregressive-Distributed Lag (ARDL) models and bounds testing for cointegration approach. Pesaran and Shin (1999) [43] and Pesaran et al. (2001) [44] initially developed the ARDL cointegration framework. The ARDL models have been used extensively over the last fifteen years to test for the existence of long-run relationships between macroeconomic variables. They are playing a very important role in the modeling of non-stationary series since they have three advantages in comparison with Johansen cointegration framework ([45]). The first one is that the ARDL framework does not require all the variables under study be integrated of the same order and it can be applied when the underlying variables are integrated of order one $(\mathrm{I}(1))$, order zero $(\mathrm{I}(0))$ or fractionally integrated. The second advantage is that the ARDL Bounding test is relatively more efficient in the case of small and finite sample data sizes. The last and third advantage is that by applying the ARDL technique, we obtain unbiased estimates for the long-run model ([46]).

The single equation ARDL model is presented by Giles (2013) [45] as follows:

$$
y_{t}=\beta_{0}+\beta_{1} y_{t-1}+\ldots+\beta_{p} y_{t-p}+\sum_{j=0}^{q_{1}} \alpha_{j} x_{1 t-j}+\sum_{j=0}^{q_{2}} \alpha_{j} x_{2 t-j}+\ldots+\sum_{j=0}^{q_{k}} \alpha_{j} x_{k t-j}+\varepsilon t
$$

where $\varepsilon_{t}$ is the random error term that is assumed to be serially independent. It is not necessary that the model contains the current values of the explanatory variables and each explanatory variable can have its own maximum lag length ([45]). The ARDL model is essentially used to implement the bounds test in order to check for the existence of the long-run relationships between the various time series investigated.

When implementing the ARDL method, we have to follow four steps. The first step is to verify that all the variables are $\mathrm{I}(0)$ and/or I(1) (none of the variables are I(2)). We use the unit root tests such as the Augmented Dickey-Fuller (ADF) ([47]), Phillips and Perron (PP) ([48]) and DF-GLS ([49]) tests to 
check that none of the variables investigated are I(2). We use also the DF-GLS test because it is well known that it is more efficient in the presence of small sample size.

The second step is to define an unrestricted error-correction model (UECM), which is given by transforming Equation (1). Suppose there are five variables that we are interested in modeling: a dependent variable, $y$, and four other explanatory variables, $x_{1}, x_{2}, x_{3}$ and $x_{4}$. We recall that a conventional ECM for cointegrated variables has the following form:

$$
\Delta y_{t}=\beta_{0}+\sum_{i=1}^{p} \beta_{i} \Delta y_{t-i}+\sum_{j=0}^{q_{1}} \gamma_{j} \Delta x_{1 t-j}+\sum_{j=0}^{q_{2}} \delta_{j} \Delta x_{2 t-j}+\sum_{j=0}^{q_{3}} \mu_{j} \Delta x_{3 t-j}+\sum_{j=0}^{q_{4}} \lambda_{j} \Delta x_{4 t-j}+\eta E C T_{t-1}+\varepsilon_{t}
$$

where ECT is the error-correction term that represents the OLS residuals derived from the long-run relationship model given by:

$$
y_{t}=\alpha_{0}+\alpha_{1} x_{1 t}+\alpha_{2} x_{2 t}+\alpha_{3} x_{3 t}+\alpha_{4} x_{4 t}+v t
$$

The error correction term is given by the following equation:

$$
\mathrm{ECT}_{t-1}=y_{t-1}-a_{0}-a_{1} x_{1 t-1}-a_{2} x_{2 t-1}-a_{3} x_{3 t-1}-a_{4} x_{4 t-1}
$$

where $\mathrm{a}_{0}, \mathrm{a}_{1}, \mathrm{a}_{2}, \mathrm{a}_{3}$ and $\mathrm{a}_{4}$ are the OLS estimates of $\alpha_{0}, \alpha_{1}, \alpha_{2}, \alpha_{3}$ and $\alpha_{4}$.

In doing so, we estimate the following model:

$$
\begin{gathered}
\Delta y_{t}=\beta_{0}+\sum_{i=1}^{p} \beta_{i} \Delta y_{t-i}+\sum_{j=0}^{q_{1}} \gamma_{j} \Delta x_{1 t-j}+\sum_{j=0}^{q_{2}} \delta_{j} \Delta x_{2 t-j}+\sum_{j=0}^{q_{3}} \mu_{j} \Delta x_{3 t-j}+\sum_{j=0}^{q_{4}} \lambda_{j} \Delta x_{4 t-j}+ \\
\theta_{0} y_{t-1}+\theta_{1} x_{1 t-1}+\theta_{2} x_{2 t-1}+\theta_{3} x_{3 t-1}+\theta_{4} x_{4 t-1}+\varepsilon_{t}
\end{gathered}
$$

This model is similar to the usual or regular error correction model but we have now replaced the error-correction term, $\mathrm{ECT}_{t-1}$ with the terms $y_{t-1}, x_{1 t-1}, x_{2 t-1}, x_{3 t-1}$ and $x_{4 t-1}$. We call this model an UECM because we are not restricting their coefficients.

This step needs the determination of appropriate lag structure of the UECM, the verification of autocorrelation of the error terms of this model, and making sure that the model is dynamically stable. Firstly, we choose the maximum lags, $p, q_{1}, q_{2}, q_{3}$ and $q_{4}$ by using the information criteria such as Akaike information criterion (AIC), Schwartz criterion (SC) or Bayesian information criterion (BIC), and Hannan-Quinn information criterion (HQ), etc. We also pay attention to the statistical significance of the coefficients in the model. Once we have our preferred specification, we check that there is no remaining autocorrelation using the LM test. If we find serial dependence of errors, we should need to lengthen the maximum lags, even if the terms are not significant. "We set a maximum lag length and then look at all possible combinations of lags within this constraint. The model with the smallest information criteria is chosen. That will involve many possible combinations. We suggest taking account of significance to reduce this set of possibilities. Start with lots of lags, and test down, not the opposite. We can omit 'intervening' lags if this is suggested by lack of significance" [45]. Normality and heteroskedasticity of the errors can also be tested. As the model has an autoregressive structure, so we have to check that the model is dynamically stable.

The third step is to implement a bounds test in order to detect if there is a cointegrating relationship between the different investigated variables by estimating the model (5) and testing the hypothesis, 
$H_{0}: \theta_{0}=\theta_{1}=\theta_{2}=\theta_{3}=\theta_{4}=0$; against the alternative that $H_{0}$ is not true. As in conventional cointegration testing, the acceptance of the null hypothesis implies the absence of a cointegrating relationship between the time series. A rejection of $\mathrm{H}_{0}$ implies that we have a long-run relationship. To decide on this, we perform an F-test.

Critical values for the F-test are supplied by Pesaran et al. (2001) [44] and complemented by Narayan (2005) [50] for smaller and finite samples. For different sample sizes, different levels of probability and different numbers of variables, there are lower and upper critical values. The lower critical value is determined by considering that all of the series are stationary on levels, whereas the upper critical value is determined by supposing that all the time series are integrated of order one. We obtain that the variables are cointegrated when the value of the F-statistic exceeds the upper critical value, whereas we reject the cointegrating relationship when the value of the F-statistic is inferior to the upper critical value. Otherwise, the test is not conclusive. Narayan (2005) [50] gives critical values for less than 80 observations.

In the fourth step, if the variables are found to be cointegrated, we estimate a long-run "levels model" given in Equation (3), as well as a separate restricted error correction model (RECM) given by Equation (2) to determine the short-run effects and the speed of adjustment If we have established that there is a long-run relationship between the various variables, we will keep all the variables in the long-run model, even some variables are individually not significant.

\subsection{Granger Causality Tests}

As noted by Granger (1988) [51], if the variables are cointegrated, we should test for short and long run causality between the dependent variable of economic growth and the explanatory variables of energy consumption, real gross fixed capital formation, employment and human capital using the restricted error correction model given in Equation (2). The long run causality is determined by testing the significance of the coefficient of the error correction term. We say that there is a long relationship between economic growth and the different explanatory variables if this coefficient of ECT $t-1$ is negative and statistically significant at a level of 5\%. The short run causality between the dependent variable of economic growth and each of the explanatory variables of energy consumption, real gross fixed capital formation, employment and human capital is determined by testing, respectively, the following hypotheses:

$\mathrm{H}_{0}: \gamma_{1}=\gamma_{2}=\ldots=\gamma_{q_{1}}=0$; implying that $x_{1}$ does not Granger-cause $\mathrm{Y}$ in the short run;

$\mathrm{H}_{0}: \delta_{1}=\delta_{2}=\ldots=\delta_{q_{2}}=0$; implying that $x_{2}$ does not Granger-cause $\mathrm{Y}$ in the short run;

$\mathrm{H}_{0}: \mu_{1}=\mu_{2}=\ldots=\mu_{q_{3}}=0$; implying that $x_{3}$ does not Granger-cause $\mathrm{Y}$ in the short run;

$\mathrm{H}_{0}: \lambda_{1}=\lambda_{2}=\ldots=\lambda_{q_{4}}=0$; implying that $x_{4}$ does not Granger-cause $\mathrm{Y}$ in the short run.

We can also test for strong long run causality between economic growth and the explanatory variables of energy consumption, real gross fixed capital formation, employment and human capital by testing, respectively, the following hypotheses:

$\mathrm{H}_{0}: \eta=\gamma_{1}=\gamma_{2}=\ldots=\gamma_{q_{1}}=0$; implying that $x_{1}$ does not strong Granger-cause Y;

$\mathrm{H}_{0}: \eta=\delta_{1}=\delta_{2}=\ldots=\delta_{q_{2}}=0$; implying that $x_{2}$ does not strong Granger-cause $\mathrm{Y}$;

$\mathrm{H}_{0}: \eta=\mu_{1}=\mu_{2}=\ldots=\mu_{q_{3}}=0$; implying that $x_{3}$ does not strong Granger-cause $\mathrm{Y}$; 
$\mathrm{H}_{0}: \eta=\lambda_{1}=\lambda_{2}=\ldots=\lambda_{q_{4}}=0$; implying that $x_{4}$ does not strong Granger-cause $\mathrm{Y}$.

All these tests are determined by the F-statistic of Wald test on coefficient restrictions in restricted ECM given in Equation (2).

\section{Empirical Results}

Contrarily to previous studies using the ARDL bounds test to cointegration in the context of VECM, our study is based on a single equation VAR model. As the ARDL bounds test is based on the assumption that the variables are $\mathrm{I}(0)$ or $\mathrm{I}(1)$, so, before applying this test, we determine the order of integration of all variables using the unit root tests. For all the variables, we use their natural logarithms. The objective is to ensure that none of the variables is integrated of order two because of spurious results and we cannot interpret the values of F-statistics provided by [44] or [50] when we have I(2) variables.

In order to check that none of the variables is integrated of order two, we apply the ADF, PP and DF-GLS tests. The results of the three tests applied to the levels and first differences of the variables are shown in Table 2. According to the three tests of ADF, PP and DF-GLS, we find that real GDP is not stationary at its level, whereas its first difference is found to be stationary. In addition, the three-unit root tests show that energy consumption is integrated of order one. The level of real gross fixed capital formation is found to be not stationary due to ADF and DF-GLS tests whereas it is shown to be stationary due to PP test at a $10 \%$ level. According to the three tests, the first difference of real gross fixed capital formation is stationary. The variable employment is found to be integrated of order one according to ADF and DF-GLS tests, while it is shown to be integrated of order zero due to PP test. Finally, human capital is found to be integrated of order zero according to ADF test, while it is shown to be integrated of order one due to PP and DF-GLS tests. Apparently, there are sometimes conflicts between the outcomes of tests; however, we can conclude that neither of variables is integrated of order two.

Table 2. Results of unit root tests.

\begin{tabular}{cccc}
\hline Variables & ADF & PP & DF-GLS \\
\hline $\mathrm{Y}$ & $2.467(0)$ & $-2.067(0)$ & $1.021(0)$ \\
$x_{1}$ & $-2.167(0)$ & $-1.910(2)$ & $-0.423(1)$ \\
$x_{2}$ & $-2.148(1)$ & $2.819(4) * * *$ & $-0.561(1)$ \\
$x_{3}$ & $-2.538(1)$ & $-3.545(4) * *$ & $-0.201(1)$ \\
$x_{4}$ & $-3.730(1)^{* *}$ & $-2.756(0)$ & $-1.592(0)$ \\
$\Delta \mathrm{Y}$ & $-3.337(0)^{*}$ & $-3.337(0)^{*}$ & $-1.648(1)^{* * *}$ \\
$\Delta x_{1}$ & $-4.485(0)^{*}$ & $-4.497(1)^{*}$ & $-2.896(0) *$ \\
$\Delta x_{2}$ & $-2.495(0)^{* *}$ & $-2.448(1)^{* *}$ & $-1.832(0) * * *$ \\
$\Delta x_{3}$ & $-3.219(0) * * *$ & $-3.188(2)$ & $-3.205(0) * *$ \\
$\Delta x_{4}$ & $-3.894(0) *$ & $-3.937(2) *$ & $-3.936(0) *$ \\
\hline
\end{tabular}

Note: $*, * *$ and $* * *$ denote the significance at the $1 \%, 5 \%$ and $10 \%$ levels, respectively; SC determines the optimal lag orders for ADF and DF-GLS tests, while the bandwidth for PP test is determined by the Newey-West using Bartlett kernel' The values between parentheses are the maximum lag length.

The results shown by the different unit root tests suggest the use of bounds test for cointegration framework. In doing so, we estimate a 1-equation VAR model (called also unrestricted ECM) given by 
Equation (5). This needs to implement the information criteria for selecting the lag-lengths. This is somewhat difficult for the lags of exogenousregressors.

Looking at the different values of Akaike information criterion (AIC), Schwarz criterion (SC) and Hannan-Quinn information criterion (HQ), we see that SC suggests a maximum lag of one. The results of lag order selection criteria are shown in Table 3.

Table 3. Results of lag order selection criteria for unrestricted ECM.

\begin{tabular}{cccc}
\hline Lag Order & AIC & SC & HQ \\
\hline 1 & -3.051 & $-2.418 *$ & -2.822 \\
2 & -3.026 & -2.173 & -2.720 \\
3 & $-3.441 *$ & -2.364 & $-3.058 *$ \\
\hline
\end{tabular}

Note: * indicates minimum value.

After that, we check for the significance of exogenous variables. As the span of the period is small and finite (41 years), we estimate the model given in Equation (5) by OLS by taking three years as the maximum lag length order for the exogenous regressors. After that, we choose only the regressors, which are significant. The selected ARDL model is of order $(1,1,3,0,0)$.

The results of diagnostic tests applied to ARDL $(1,1,3,0,0)$ are shown in Table 4. When we check for the serial independence of the errors of this model using the Breush-Godfrey Lagrange multiplier (LM) test, we find that they are serially independent at the 5\% level up to order twelve.

Table 4. Results of diagnostic tests applied to ARDL $(1,1,3,0,0)$.

\begin{tabular}{ccccccc}
\hline & Breush-Godfrey LM Test & \multicolumn{2}{c}{ Normality Test } & \multicolumn{2}{c}{ ARCH Test } \\
\hline Lag & LM stat & $\boldsymbol{p}$-value & $\chi^{2}$ stat & $\boldsymbol{p}$-value & $\chi^{2}$ stat & $\boldsymbol{p}$-value \\
\hline 1 & 2.994 & 0.083 & 0.812 & 0.666 & $0.061(1)$ & 0.803 \\
2 & 1.529 & 0.216 & & & & \\
3 & 3.127 & 0.077 & & & & \\
4 & 3.566 & 0.058 & & & & \\
5 & 0.041 & 0.839 & & & & \\
6 & 0.001 & 0.970 & & & & \\
7 & 1.509 & 0.219 & & & & \\
8 & 0.384 & 0.535 & & & & \\
9 & 0.0001 & 0.990 & & & & \\
10 & 0.829 & 0.362 & & & & \\
11 & 0.933 & 0.333 & & & & \\
12 & 0.121 & 0.727 & & & & \\
\hline
\end{tabular}

Value between parentheses is the order of diagnostic test.

The $p$-values corresponding to the Jarque-Bera normality test indicate that we accept at a $5 \%$ level the normality of the error disturbances. The result of the autoregressive conditional heteroskedasticity (ARCH) test shows that the errors of the ARDL model are not heteroskedastic as its $p$-value is equal to 0.803. Finally, before proceeding to the bounds testing, we verify for the inverse roots of the autoregressive characteristic of our unrestricted ECM. As shown by Figure 2, all these roots are inside the unit circle, which implies that the ARDL model is dynamically stable. 


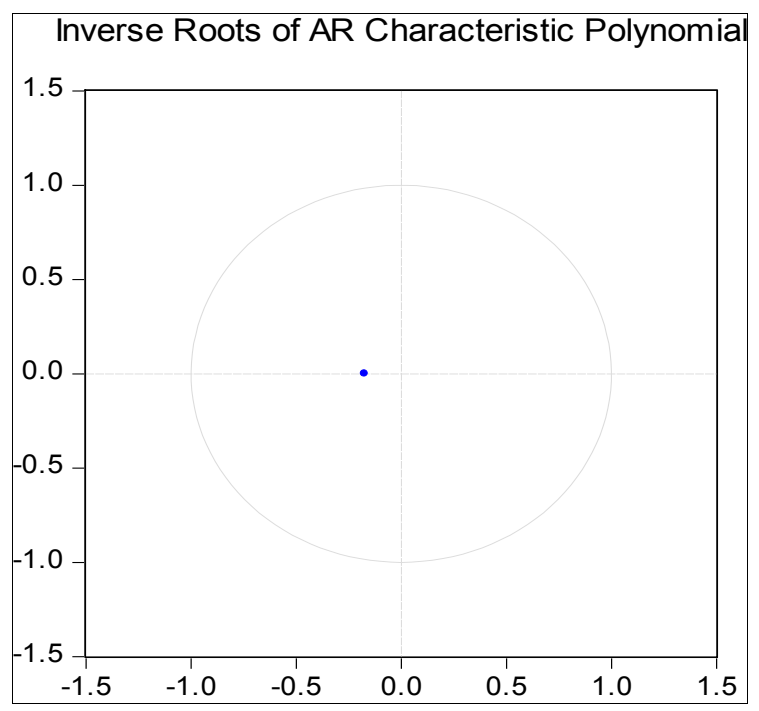

Figure 2. The inverse roots of the associated characteristic ARDL model.

Since the ARDL model passes all diagnostic tests without problem, we apply the bounds testing by checking for the null hypothesis, $H_{0}: \theta_{0}=\theta_{1}=\theta_{2}=\theta_{3}=\theta_{4}=0$. Results of the test are shown in Table 5 . The value of F-statistic is equal to 5.355. Therefore, when we go to the bounds test tables of critical values, we use the number of regressors $(\mathrm{k}=4)$. We have not constrained the intercept of our model, and there is no linear trend term included in the ARDL model. As the number of observations is small $(\mathrm{T}=42)$, critical values are collected from [50] for $\mathrm{T}=40$. The lower and upper bounds at the $10 \%, 5 \%$, and $1 \%$ significance levels are equal to [2.483, 3.647], [2.962, 4.268], and [4.045, 5.898], respectively.

Table 5. The results of ARDL bounds test.

\begin{tabular}{ccc}
\hline \multicolumn{3}{c}{ Bounds Testing for Cointegration } \\
\hline F-statistic & Optimal lag length & F-statistic \\
\hline $\mathrm{F}_{\mathrm{Y}}\left(\mathrm{Y} / x_{1}, x_{2}, x_{3}, x_{4}\right)$ & $1,1,3,0,0$ & $5.355 * *$ \\
\hline & Critical Values \\
\hline Significance level & Lower bounds I(0) & Upper bounds I(1) \\
\hline 1\% level & 4.045 & 5.898 \\
$5 \%$ level & 2.962 & 4.268 \\
$10 \%$ level & 2.483 & 3.647 \\
\hline
\end{tabular}

Note: The asterisks * $* *$ and $* * *$ denote the significance at $1 \%, 5 \%$ and $10 \%$ levels, respectively.

As the value of the F-statistic exceeds the upper bound at the 5\% significance level, we can conclude that there is a relationship between economic growth and the various explanatory variables (energy consumption, real gross fixed capital formation, employment and human capital) in the long run.

For testing the dynamic causal relationships between economic growth and the various explanatory variables, we estimate the long run equilibrium model given in Equation (3) by OLS, construct the residuals series, deduce the error correction terms given in Equation (4) and estimate by OLS the restricted ECM given in Equation (2). The results show that the coefficient of the error-correction term, $\mathrm{ECT}_{t-1}$, is negative and significant at $1 \%$ level. If the result of the ARDL bounds test shows that there is cointegration between the variables, but the coefficient of the error correction term is positive or negative, but not significant, the model may be misspecified. In addition, if the coefficient of the error- 
correction term is smaller than -1 , it makes no sense and it implies that there is an "over-correction" towards equilibrium ([45]). This is expected because there is cointegration between the various investigated variables. The coefficient of the error-correction term represents the speed of adjustment per period after a short-run shock to the equilibrium relationship. It is equal to -0.637 . The magnitude of this coefficient implies that the speed of adjustment is rapid. Nearly $64 \%$ of any disequilibrium between economic growth and the inputs is corrected within one year. Thus, given the negative ECT sign, real GDP "moves" to close the disequilibrium gap within two years.

The restricted error correction model, which represents short run dynamics, passes also the diagnostic tests without problems. Results of diagnostic tests are shown in Table 6. Figure 3 shows that the model is dynamically stable because the only root is inside the unit circle and it lies on the X-axis. Accordingly, the short-run dynamics associated with the model are not complicated.

Table 6. Results of diagnostic tests applied to residuals of ECM.

\begin{tabular}{ccccccc}
\hline \multicolumn{2}{c}{ LM test } & \multicolumn{5}{c}{ Normality test } \\
\multicolumn{2}{c}{ ARCH test } \\
\hline Lag & $\chi^{2}$ stat & $\boldsymbol{p}$-value & $\chi^{2}$ stat & $\boldsymbol{p}$-value & $\chi^{2}$ stat & $\boldsymbol{p}$-value \\
\hline 1 & 1.964 & 0.161 & 1.686 & 0.430 & $0.693(1)$ & 0.405 \\
2 & $5.48 \times 10^{-5}$ & 0.994 & & & & \\
3 & 2.044 & 0.152 & & & & \\
4 & 2.507 & 0.113 & & & & \\
5 & 1.177 & 0.277 & & & & \\
6 & 0.013 & 0.906 & & & & \\
7 & 2.416 & 0.120 & & & & \\
8 & 0.901 & 0.342 & & & & \\
9 & 0.225 & 0.634 & & & & \\
10 & 0.679 & 0.409 & & & & \\
11 & 0.701 & 0.402 & & & & \\
12 & 0.264 & 0.606 & & & & \\
\hline
\end{tabular}

Values between parentheses are the order of diagnostic tests.

As shown in Table 6, the results of LM test applied to residuals of ECM imply that the error disturbances are serially independent up to order twelve.

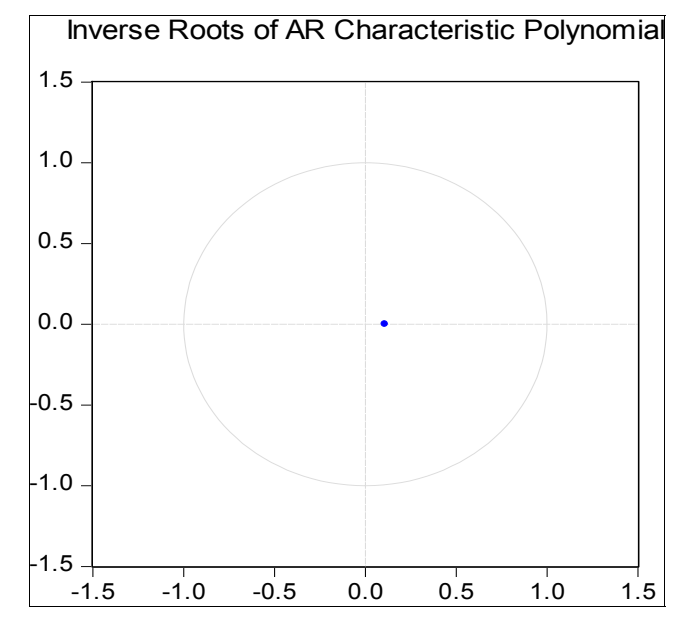

Figure 3. The inverse roots of the associated characteristic RECM. 
As we find that the variables are cointegrated when the economic output is the dependent variable, we should employ the Granger causality test in the ECM to determine which exogenous variables can cause economic growth for Saudi Arabia. Long-run causality is determined by the t-significance of the one period lagged error-correction term $\mathrm{ECT}_{t-1}$, whereas short run causality is determined by the joint significance $\mathrm{F}$ tests of the lagged explanatory variables. The results of different types of short and long run Granger causality are shown in Table 7. In the short run, the conventional inputs (capital and employment) Granger cause economic growth at $1 \%$ level, whereas energy consumption and human capital Granger cause economic growth at a level of 5\%. For the long-run causality, the estimated coefficient of $\mathrm{ECT}_{t-1}$ is negative and significant at a level of $1 \%$, implying that there is unidirectional causality running from energy consumption, capital, employment and human capital to economic output in the long run. When checking for the strong long run causality, we find that all inputs Granger cause economic growth at even $1 \%$ level.

Table 7. The results of Granger causality tests.

\begin{tabular}{|c|c|c|c|c|c|}
\hline \multirow{2}{*}{ Depend. Variable: $\Delta y$} & $\sum \Delta x_{1 j}$ & $\sum \Delta x_{2 j}$ & $\sum \Delta x_{3 j}$ & $\sum \Delta x_{4 j}$ & Long-run causality \\
\hline & \multicolumn{4}{|c|}{ F statistics [ $p$-values] } & $\mathbf{E C T}_{t-1}[$ t-statistic] \\
\hline Short-run causality & $5.98 * *[0.05]$ & $17.21 * * *[0.00]$ & $6.88 *[0.00]$ & $4.50 * *[0.03]$ & $-0.637 *[-4.44]$ \\
\hline Strong Long-run causality & $20.19 *[0.00]$ & $35.50 *[0.00]$ & $21.63 *[0.00]$ & $19.96 *[0.00]$ & \\
\hline
\end{tabular}

Note: The asterisks $* * *, * *$ and $*$ denote the significance at the $1 \%, 5 \%$ and $10 \%$ levels, respectively.

For robustness, as the unit root tests suggest that the five time series can be I(1), we can also use the multivariate cointegration approach of [52,53]. Before applying this test, we determine the lag length for the VAR model. Due to the criterion of AIC, the maximum lag length is equal to 1 whereas it is equal to 5 according to the criteria of SC.

For a lag length equal to 1, the results of trace and Max-Eigen tests are summarized for the five cases in Table 8. According to Max-Eigen test, there is only one cointegrating relationship between the five variables for all the five cases. However, the trace test gives that there are 3 cointegrating relationships for the first case (no intercept or trend in CE or test VAR), and only 1 cointegrating relationship for the four remaining cases. We can conclude that there is significant evidence in favor of only one cointegrating relationship between the five variables, as the second case (intercept but no trend in CE, no intercept in VAR) is more suitable for our study.

Table 8. Results of trace and Max-Eigen tests.

\begin{tabular}{cccccc}
\hline Data Trend & None & None & Linear & Linear & Quadratic \\
\hline \multirow{2}{*}{ Rank or No. of CEs } & $\begin{array}{c}\text { No Intercept } \\
\text { No Trend }\end{array}$ & $\begin{array}{c}\text { Intercept } \\
\text { No Trend }\end{array}$ & $\begin{array}{c}\text { Intercept } \\
\text { No Trend }\end{array}$ & $\begin{array}{c}\text { Intercept } \\
\text { Trend }\end{array}$ & $\begin{array}{c}\text { Intercept } \\
\text { Trend }\end{array}$ \\
\hline & Number of Cointegrating relations by & model at 5\% level & \\
\hline Trace test & 3 & 1 & 1 & 1 & 1 \\
Max-Eigen test & 1 & 1 & 1 & 1 & 1 \\
\hline
\end{tabular}

When estimating the vector error correction model (VECM), the coefficient of error correction term is negative and statistically significant in only the equation where the dependent variable is economic growth. This implies that the only long run relationship exists when economic growth is the dependent 
variable. The results given by the multivariate cointegration approach of $[52,53]$ confirm those obtained using the ARDL bounds testing to cointegration framework.

\section{Discussion}

According to our findings, we affirm that energy consumption strongly causes economic growth, and these results are contradictory to those obtained by previous studies for Saudi Arabia ([31-38]). Hence, our results support the energy-led growth hypothesis. The economic growth of Saudi Arabia may benefit from the extensive use of oil and the high subsidization of oil price. Firstly, energy plays an important role as an input in the production function. From that perspective, the results show a positive contribution of energy consumption to economic activity. In addition, Saudi Arabia is subsidizing fossil fuel products (oil and natural gas products) and electricity. This subsidization is mainly in favor of domestic consumption and domestic and foreign investors.

Saudi Arabia is one of the largest energy consumers in the world. As it is the world's first largest producer of oil and due to the low levels of energy prices, there is a vast wasteful use of energy. Saudi Arabia consumes more than one quarter of its energy production. Total energy primary production is equal to 3.29 times the total energy consumption in 2012 ([54]). The growth rate of total energy consumption is equal to $5.6 \%$ (2.2\% in the world) per year over the period of 2000-2012 in Saudi Arabia. It is one of the countries, which have a high growth rate of energy consumption in the world after China (7.0\%), and Kazakhstan (6.6\%). In addition, comparatively to other countries, energy intensity of GDP is very high in Saudi Arabia. For example, for the Saudi Arabia energy intensity of GDP at constant purchasing power parities (expressed in koe/\$2005) is equal to 0.310 in 2012 , while it is equal to only 0.184 in the world ([54]).

As energy consumption leads to economic growth, energy conservation measures can restrain the economic development of the country. Hence, the energy conservation measures should be based on energy efficiency and addressed with caution. Such measures should include the use of various tariff rates, insulation materials in buildings, more training of energy-efficiency personnel, certification for energy managers and auditors, energy efficiency information and awareness, energy efficiency labels and standards for new equipment, energy audits, and enforcement of energy conservation laws ([55,56]).

According to [55], the use of renewable energy resources (wind and solar) adding to energy efficiency measures can lead to a reduction of 10\% in energy consumption in Saudi Arabia. These measures can benefit Saudi Arabia about $\$ 6$ billion per year as supplementary revenue from fuel exports ([55]). The share of renewable energies in primary consumption is less than $0.1 \%$ in Saudi Arabia while it is $12.9 \%$ in the world. For example, in Norway that is a natural gas and oil producing country, renewable energies represent about $43.1 \%$ of primary energy consumption in 2012.

Energy subsidy plays a major role in the overuse of energy in Saudi Arabia. In Saudi Arabia, energy subsidies were estimated at $10 \%$ of its GDP in 2011. These subsidies can create distortions in markets and incentives for wasteful ([57]).

\section{Conclusions}

This study tests the energy-led growth hypothesis by examining the relationship between real GDP and energy consumption, employment, real fixed capital formation and human capital using the ARDL 
bounds testing to cointegration approach for the case of Saudi Arabia. Our results show the presence of a long run relationship between the various variables. Robustness of the results of ARDL testing to cointegration is tested by employing the Johansen multivariate cointegration technique. The two approaches give approximately the same results. All the inputs (conventional and non-conventional) Granger cause economic growth in both the short and long runs. While our results show the importance of energy use to economic activity through the various channels of production, consumption and investment in Saudi Arabia, this must not neglect its environmental consequences and the investment in renewable energy sources. Our findings reaffirm the previous studies stating that energy is not neutral to economic growth.

We are motivated by testing the energy-led growth hypothesis due to the impact of the various conservation policies on economic growth. Energy policies are based, in part, on the energy-growth nexus. Knowing the relationship between economic growth and energy use can help policy makers taking the best decisions of energy management, which are important for environmental and climate changes.

As we find that energy consumption Granger causes economic growth, the adoption of energy conservation policies can limit Saudi economic growth. Hence, policy measures should be based on energy efficiency and the investment in renewable energy sources such as solar and wind where Saudi Arabia has also abundant resources.

Energy efficiency plays both roles. It saves money that can be used in the investment in renewable energies and it reduces greenhouse gases to meet the international commitments on climate change. The investment in renewable energies should help Saudi Arabia to be prepared in the long run to the low carbon economy that is based on clean technologies. Adding to that as suggested by the International Monetary Fund, energy subsidy reforms should be planned in Saudi Arabia.

As energy is overused in Saudi Arabia, future researches on this subject should be dedicated to energy efficiency and environmental efficiency. Reducing the conventional energy use in developed and developing countries is considered an important element in the world's ability to grow sustainably. Likewise, reducing energy consumption is considered a practical solution to many of today's common challenges including global energy shortages; mitigating against further changes in the climate; and health impacts of local air and water pollution. Understanding the factors that influence fluctuations in energy use are of first-order importance for academics and policymakers.

\section{Acknowledgments}

The research leading to this paper was sponsored by Najran University, Kingdom of Saudi Arabia.

\section{Author Contributions}

Atef Saad Alshehry collected the data, whereas Mounir Belloumi conceived and performed the experiments using the analysis tools. Both authors analyzed the data and wrote the paper.

\section{Conflicts of Interest}

The authors declare no conflict of interest. 


\section{References}

1. Stern, D.I. Energy and economic growth in the USA: A multivariate approach. Energy Econ. 1993, $15,137-150$.

2. Stern, D.I. A multivariate cointegration analysis of the role of energy in the US macroeconomy. Energy Econ. 2000, 22, 267-283.

3. Cleveland, C.J.; Costanza, R.; Hall, C.A.S.; Kaufmann, R.K. Energy and the US economy: A biophysical perspective. Science 1984, 225, 890-897.

4. Salamaliki, P.K.; Venetis, I.A. Energy consumption and real GDP in G-7: Multi-horizon causality testing in the presence of capital stock. Energy Econ. 2013, 39, 108-121.

5. Stern, D.I. The role of energy in economic growth. Ecol. Econ. Rev. 2011, 1219, 26-51.

6. Pirlogea, C.; Cicea, C. Econometric perspective of the energy consumption and economic growth relation in European Union. Renew. Sustain. Energy Rev. 2012, 16, 5718-5726.

7. Kraft, J.; Kraft, A. On the relationship between energy and GNP. J. Energy Dev. 1978, 3, 401-403.

8. Menegaki, A.N. On energy consumption and GDP studies; A meta-analysis of the last two decades. Renew. Sustain. Energy Rev. 2014, 29, 31-36.

9. Akarca, A.T.; Long, T.V. Relationship between energy and GNP: A reexamination. J. Energy Dev. 1980, 5, 326-331.

10. Erol, U.; Yu, E.S.H. On the causal relationship between energy and income for industrialized countries. J. Energy Dev. 1987, 13, 113-122.

11. Yu, E.S.H.; Hwang, B. The relationship between energy and GNP: Further results. Energy Econ. 1984, 6, 186-190.

12. Engle, R.F.; Granger, C.W.J. Co-integration and error correction: Representation, estimation, and testing. Econometrica 1987, 55, 251-276.

13. Johansen, S.; Juselius, K. Maximum likelihood estimation and inference on cointegration with applications to the demand for money. Oxf. Bull. Econ. Stat. 1990, 52, 169-210.

14. Cheng, B.S.; Lai, T.W. An investigation of cointegration and causality between energy consumption and economic activity in Taiwan. Energy Econ. 1997, 19, 435-444.

15. Chang, T.; Fang, W.; Wen, L.F. Energy consumption, employment, output and temporal causality: Evidence from Taiwan based on cointegration and error-correction modelling techniques. Appl. Econ. 2001, 33, 1045-1056.

16. Ghali, K.H.; El-Sakka, M.I.T. Energy and output growth in Canada: A multivariate cointegration analysis. Energy Econ. 2004, 26, 225-238.

17. Soytas, U.; Sari, R. The relationship between energy and production: Evidence from Turkish manufacturing industry. Energy Econ. 2007, 29, 1151-1165.

18. Yuan, J.; Kang, J.; Zhao, C.; Hu, Z. Energy consumption and economic growth: Evidence from China at both aggregated and disaggregated levels. Energy Econ. 2008, 30, 3077-3094.

19. Stern, D.I.; Enflo, K. Causality between energy and output in the long-run. Energy Econ. 2013, 39, 135-146.

20. Sari, R.; Ewing, B.T.; Soytas, U. The relationship between disaggregate energy consumption and industrial production in the United States: An ARDL approach. Energy Econ. 2008, 30, 2302-2313. 
21. Shahbaz, M.; Tang, C.F.; Shahbaz Shabbir, M. Electricity consumption and economic growth nexus in Portugal using cointegration and causality approaches. Energy Policy 2011, 39, 3529-3536.

22. Lee, C.C.; Chang, C.P.; Chen, P.F. Energy-income causality in OECD countries revisited: The key role of capital stock. Energy Econ. 2008, 30, 2359-2373.

23. Shahateet, M.I. Modeling Economic Growth and Energy Consumption in Arab Countries: Cointegration and Causality Analysis. Int. J. Energy Econ. Policy 2014, 4, 349-359.

24. Yildirim, E.; Aslan, A. Energy consumption and economic growth nexus for 17 highly developed OECD countries: Further evidence based on bootstrap-corrected causality tests. Energy Policy 2012, 51, 985-993.

25. Yalta, T.; Cakar, H. Energy consumption and economic growth in China: A reconciliation. Energy Policy 2012, 41, 666-675.

26. Dufour, J.-M.; Pelletier, D.; Renault, E. Short run and long run causality in time series: Inference. J. Econometr. 2006, 132, 337-362.

27. Hill, J.B. Efficient tests of long-run causation in trivariate VAR processes with a rolling window study of the money-income relationship. J. Appl. Econometr. 2007, 22, 747-765.

28. Ayres, R.; Voudouris, V. The economic growth enigma: Capital, labor and useful energy? Energy Policy 2014, 64, 16-28.

29. Alkhathlan, K.; Alam, M.; Javid, M. Carbon dioxide emissions, energy consumption and economic growth in Saudi Arabia: A multivariate cointegration analysis. Br. J. Econ. Manag. Trade 2012, 2 , 327-339.

30. Alqudair, K. Causal Relationship between Energy Consumption and Economic Growth in the Kingdom of Saudi Arabia. J. Energy Dev. 2012, 37, 129-142.

31. Al-Iriani, M.A. Energy-GDP relationship revisited: An example from GCC countries using panel Causality. Energy Policy 2006, 34, 3342-3350.

32. Mehrara, M. Energy consumption and economic growth: The case of oil exporting countries. Energy Policy 2007, 35, 2939-2945.

33. Squalli, J. Electricity consumption and economic growth: Bounds and causality analyses for OPEC members. Energy Econ. 2007, 29, 1192-1205.

34. Narayan, P.K.; Smyth, R. Multivariate granger causality between electricity consumption, exports and GDP: Evidence from a panel of Middle Eastern countries. Energy Policy 2009, 37, 229-236.

35. Sadorsky, P. Trade and energy consumption in the Middle East. Energy Econ. 2011, 33, 739-749.

36. Hossein, A.; Yazdan, G.F.; Ehsan, A.G. The Relationship between Energy Consumption, Energy Prices and Economic Growth: Case Study (OPEC Countries). OPEC Energy Rev. 2012, 36, 272-286.

37. Damette, O.; Seghir, M. Energy as a driver of growth in oil exporting countries? Energy Econ. 2013, 37, 193-199.

38. Mohammadi, H.; Parvaresh, P. Energy consumption and output: Evidence from a panel of 14 oil-exporting countries. Energy Econ. 2014, 41, 41-46.

39. WDI. World Development Indicators; World Bank: Washington, DC, USA, 2013.

40. The Conference Board Total Economy Database ${ }^{\mathrm{TM}}$, January 2014. Available online: Http://www.conference-board.org/data/economydatabase/ (accessed on 13 May 2014).

41. Balasubramanyam, V.N.; Salisu, M.A.; Sapsford, D. Foreign direct investment and growth in EP and IS countries. Econ. J. 1996, 106, 92-105. 
42. Belloumi, M. The relationship between trade, FDI and economic growth in Tunisia: An application of the autoregressive distributed lag model. Economic Systems 2014, 38, 269-287.

43. Pesaran, M.; Shin, Y. An Autoregressive Distributed Lag Modeling Approach to Cointegration Analysis. In Proceedings of the Econometrics and Economic Theory in the 20th Century: The Ragnar Frisch centennial Symposium; Econometric Society Monographs Book 31; Strom, S., Ed.; Cambridge University Press: Cambridge, UK, 1999.

44. Pesaran, M.H.; Shin, Y.; Smith, R. Bounds testing approaches to the analysis of level relationships. J. Appl. Econometr. 2001, 16, 289-326.

45. Giles, D.E. ARDL models-Part II-Bounds Tests. Available online: http://davegiles.blogspost.com/ 2013/06/ardl-models-part-ii-bounds-tests.html (accessed on 13 April 2014).

46. Harris, R.; Sollis, R. Applied Time Series Modelling and Forecasting; Wiley: Chichester, UK, 2003.

47. Dickey, D.A.; Fuller, W.A. Distribution of the estimators for autoregressive time series with a unit root. J. Am. Stat. Assoc. 1979, 74, 427-431.

48. Phillips, P.C.B.; Perron, P. Testing for a unit root in time series regression. Biometrika 1988, 75, 335-346.

49. Elliot, G.; Rothenberg, T.J.; Stock, J.H. Efficient tests for an autoregressive unit root. Econometrica 1996, 64, 813-836.

50. Narayan, P.K. The saving and investment nexus for China: Evidence from cointegration tests. Appl. Econ. 2005, 37, 1979-1990.

51. Granger, C.W.J. Causality, cointegration and control. J. Econ. Dyn. Control 1988, 12, 551-559.

52. Johansen, S. Estimation and hypothesis testing of cointegrated vectors in Gaussian vector autoregressive models. Econometrica 1991, 59, 1551-1580.

53. Johansen, S. Likelihood-Based Inference in Cointegrated Vector Autoregressive Models; Oxford University Press: Oxford, UK, 1995.

54. BP Statistical Review of World Energy June 2013. Available online: http://www.bp.com/ statisticalreview (accessed on 12 May 2014).

55. Alyousef, Y.; Abu-ebid, M. Energy Efficiency Initiatives for Saudi Arabia on Supply and Demand Sides, Energy Efficiency-A Bridge to Low Carbon Economy; Morvaj, Z., Ed.; InTech: Rijeca, Croatia, 2012.

56. Alshehri, A.; Hussain, A.; Mobarak, Y. Energy-conversion measures in the industries of Saudi Arabia and development of methodology for certification of energy personnel in the Kingdom. Energy Policy 2014, 64, 203-208.

57. International Monetary Fund (IMF). Energy Subsidies in the Middle East and North Africa: Lessons for Reform. Available online: http://www.imf.org/external/np/fad/subsidies/pdf/menanote.pdf (accessed on 21 April 2014).

(C) 2015 by the authors; licensee MDPI, Basel, Switzerland. This article is an open access article distributed under the terms and conditions of the Creative Commons Attribution license (http://creativecommons.org/licenses/by/4.0/). 